\title{
Central precocious puberty
}

INSERM

\section{Source}

INSERM. (1999). Orphanet: an online rare disease and orphan drug data base. Central precocious puberty. ORPHA:759

Central precocious puberty (CPP), also referred to as gonadotropin dependent precocious puberty, is an endocrine-related developmental disease characterized by the onset of pubertal changes, with development of secondary sexual characteristics and accelerated growth and bone maturation, before the normal age of puberty (8 years in girls and 9 years in boys). 